\title{
CONSIDERAÇÕES PRELIMINARES SOBRE O JOGO ANTITÉTICO NA HISTORIOGRAFIA DE SALUSTIO
}

\author{
Míriam Barcellos Goettems \\ Universidade Federal do Rio Grande do Sul
}

Resumo: 0 presente ensaio faz uma análise do prólogo da monografia De Coniuratione Catilinae, de Salústio, ressaltando dois pontos: 1. a função paradigmática desse proêmio, a partir do levantamento e estudo dos pares antitéticos nele presentes, os quais fixam um modelo dualístico que se estrutura, sintagmaticamente, ao longo da narrativa; 2. a definição do papel do historiador que emerge desses capítulos iniciais da obra, nos quais se evidencia a identidade de valor entre "dicere"e facere".

Palavaas-chave: Salústio, antítese, dualismo metafísico, discere = facere, $\cdot$ historiografia pragmática.

"Por isso, quando enfim meu esplrito descansou de tantos infortúnios e riscos, decidi manter bem longe da politica 0 resto da minha vida $e$ (...) tomei a decisão de escrever a história do povo romano, extraindo dela os fatos que me pareciam dignos de registro (...)." (De C.C. 4, 1-2) ${ }^{1}$

Com essas palavras, que abrem o capitulo final do prólogo de sua obra De Coniuratione Catilinae, Salústio traz a nosso conhecimento dois dados autobiográficos que, unidos, fazem dele uma figura impar na historiografia latina.

0 primeiro desses dados diz respeito ao fato de que, antes de se dedicar à carreira de historiador, Salústio foi um político - e dos mais ativos, segundo nos informam outras fontes biográficas. Sendo assim, parece-nos óbvio supor que ele possuísse aquela qualidade que Luciano de Samósata - em seu Como se Deve Escrever a História - entende como essencial em alguém que se pretende historiador: o senso político (Besselaar, 1958, p. 14).

0 segundo dado a ressaltar no trecho de Salústio relaciona-se à sua decisão de escrever não toda a história do povo romano mas tão-somente aqueles fatos que the parecessem dignos de lembrança. Com essa decisão, Salústio torna-se 0 introdutor de um tipo de manifestação histórica - a monografia - até então inédita em Roma, onde a historiografia estava dominada basicamente pela analistica, a que se viera juntar, já na própria época de Salústio, a forma dos "comentarii", adotada por César.

1. Valemo-nos aqui da tradução do De Coniuratione Catilinae realizada pelo Prof. Antônio da Silveira Mendonça, que se encontra referida na bibliografia. 
Diferentemente dos anais e dos comentários, a monografia salustiana não é um mero registro de acontecimentos: seu objetivo precípuo é mostrar a existência de uma relação de causa e efeito que explica os fatos, objetivo esse cuja origem 0 próprio historiador nos relata ao afirmar:

"Mas eu, que já li muito, que ouvi contar muitos feitos eminentes realizados pelo povo romano, na paz como na guerra, no mar como na terra, veio-me ao acaso o desejo de indagar que causas tornaram possíveis tão grandes façanhas." (De C.C. 53, 2)

Após muito refletir, eis sua conclusão:

"(...) uma coisa me pareceu palpável: a coragem extraordinária de uns poucos cidadãos tinha feito tudo e por ela é que se dera que a pobreza superara a riqueza, 0 pequeno número, a multidão das pessoas. " (De C.C. 53, 4)

Essa "coragem extraordinária" ( "egregiam uirtutem" ), no entanto, abandonara Roma:

"Mas quando o luxo e a ociosidade corromperam a cidade, a república d̀ custa de sua grandeza sustentava os vicios de seus generais e magistrados; e, como uma mãe cuja fecundidade se exauriu, por muito tempo em Roma realmente não houve nenhum homem de grande valor." (De C.C. 53,5 )

Tendo seu pensamento dominado por esse conceito de degeneração moral e política que envolve a perda da "uirtus" romana, Salústio orienta-se para a elaboração de monografias centradas em acontecimentos - a conspiração de Catilina e a guerra contra Jugurta - que não apenas comprovam essa degeneração como também possibilitam ao historiador exercitar 0 senso político que efetivamente possuía.

A escolha adequada dos acontecimentos que narra permite a Salústio inserir-se com facilidade no ideal tucididiano de historiador: alguém que mostra os fatos do passado com vistas a transformá-los em lições para o futuro, na crença de que "a história é o ensinamento político por excelência" (Besselaar, 1958, p.11). Em outras palavras, Salústio integra-se ao grupo dos que praticam a "historiografia pragmática" de Políbio, no sentido de que dirige seus relatos a "homens práticos", quer dizer, a políticos e militares, acreditando no poder educativo da história (Besselaar, 1958, p. 13).

Essencial para que essa função educativa seja cumprida pela obra de Salústio é a recorrência, nela, de uma figura que, como afirma Barthes, é uma das mais estáveis dentre todas as que, ao longo dos séculos, foram propostas pela arte retórica: a antítese (Barthes, 1970, p. 33). Nada mais natural que assim seja, tendo em vista que, conforme já frisamos, é dominante, no pensamento salustiano, a idéia 
de degeneração moral e política - e, portanto, de oposição entre passado e presente - que envolve a perda da "uirtus" pelos romanos.

Levando em consideração esses fatos, propusemo-nos a realizar um estudo da antítese na obra de Salústio, detendo-nos, neste momento, no De Coniuratione Catilinae -mais especificamente, no seu prólogo, que compreende os quatro primeiros capítulos da obra.

0 primeiro dado a ressaltar é que esse proêmio exerce uma função paradigmática em relação ao restante da narrativa, na medida em que fixa o modelo teórico que serve de sustentáculo para toda a monografia: o dualismo.

Os pares opositivos que podem ser destacados no prólogo são vários. Ressaltaremos, em primeiro lugar, os que aparecem no capítulo 1, apontando todos os termos em sua forma de nominativo e, preferencialmente, na ordem em que figuram no texto, para facilitar a compreensão.

$\begin{array}{rll}\text { Coluna 1 } & \times & \text { Coluna 2 } \\ \text { homines } & \times & \text { cetera animalia } \\ \text { animus } & \times & \text { corpus } \\ \text { imperium } & \times & \text { seruitium } \\ \text { homines et di } & \times & \text { beluae } \\ \text { ingenium } & \times & \text { uis (corporis) } \\ \text { gloria } & \times & \text { silentium } \\ \text { memoria } & & \text { uita } \\ \downarrow & \times & \downarrow \\ \text { longa } & & \text { breuis } \\ \text { uirtus } & & \text { diuitiarum et formae gloria } \\ \downarrow & \times & \\ \text { fluxa atque fragilis. (De C.C. 1, 1-4) }\end{array}$

Todas essas oposições são feitas de acordo com o dualismo metafísico, desenvolvido por Platão, em que a importância é atribuída aos elementos da primeira coluna. Se os rotulamos de partícipes do "logos", designando os da segunda coluna como pertencentes à "physis", podemos aplicar à posição de Salústio o que afirma Gerd Bornheim acerca do pensamento metafísico:

"Todo pensamento metafísico se move no espaço entre o logos e a physis, e de tal maneira que o privilégio é emprestado ao logos em detrimento da physis." (Bornheim, 1977, p.26)

No início do capitulo 2 da monografia, outro par opositivo vem juntar-se aos acima arrolados:

$\begin{array}{ccc}\text { Coluna } 1 & \mathrm{x} & \text { Coluna } 2 \\ \text { passado } & \mathrm{x} & \text { presente. (De C.C. 2) }\end{array}$


Também aqui o primeiro elemento (o passado) tem supremacia sobre 0 segundo (o presente), já que 0 autor sublinha o caráter degenerativo da história: no início, diz ele, "a vida dos homens se passava sem ambiçóes, cada um contente com o que tinha" ("uita hominum sine cupiditate agitabatur, sua cuique satis placebant") (De C.C. 2, 1); depois, no entanto, o desejo de dominar tornou-se 0 motivo das guerras, e os homens começaram a pensar que a maior glória estava no maior dos impérios (De C.C. 2, 2). A partir dal, multiplicam-se os pares antitéticos:

$\begin{array}{rll}\begin{array}{r}\text { Coluna 1 } \\ \text { labor }\end{array} & \mathrm{x} & \begin{array}{l}\text { Coluna } 2 \\ \text { desidia }\end{array} \\ \text { continentia } & \mathrm{x} & \text { lubido } \\ \text { aequitas } & \mathrm{x} & \text { superbia. (De C.C. 2, 5) }\end{array}$

Continuando a avaliar como superiores os elementos da primeira coluna, Salústio permanece dentro do pensamento metafísico:

"Tudo se passa como se a physis devesse ser descartada, a fim de que o logos chegasse a ser plenamente ele mesmo." (Bornheim, 1977, p. 26)

E já que falamos em "logos", aproveitamos para lembrar o poder que, segundo Salústio, detém a palavra: o poder de superação do passageiro, da morte, do desgaste, desde que o ser humano, "aplicado a alguma atividade" ("aliquo negotio intentus"), procure tornar-se famoso por alguma façanha ilustre ou por alguma ocupação dignificante (De C.C. 2, 9). Ao contrário, aqueles que, "entregues ao ventre e ao sono" ("dediti uentri atque somno"), passam pela vida "ignorantes $e$ abrutalhados (...) como andarilhos" (indocti incultique (...) sicuti peregrinantes") (De C.C. 2, 8), são seres cuja vida e cuja morte estão em pé de igualdade, "pois de ambas se fará silêncio" ("quoniam de utraque siletur") (De C.C. 2, 8). Uma vida que se desgasta nos apetites do corpo não merece que a palavra a retenha da morte.

0 valor da fala, do discurso, da memória está claramente expressso no capítulo 3 , onde se indicam as duas formas de conduta a serem seguidas por aqueles que desejam ser úteis à pátria:

"É belo servir bem à pátria, falar bem dela também não é descabido; (...)." (De C.C. 3, 1)

Não se trata propriamente de uma nova oposição - entre "bene facere" e "bene dicere" - que está sendo apresentada aqui: são simplesmente dois caminhos distintos que, dependendo da natureza de cada um ('a natureza oferece a cada um o seu caminho" - "aliud alii natura iter ostendit" - De C.C. 3, 1), os homens podem seguir para alcançar a consecução de um mesmo objetivo.

Observe-se, por outro lado, que, "embora năo seja nada igual a glória do que escreve a historia $e$ do que a faz" ("tametsi haudquaquam par gloria sequitur scriptorem et auctorem rerum") (De C.C. 3, 2), Salústio estabelece, de certa forma, 
uma equivalência de valor entre esses dois caminhos, ao ressaltar as grandes dificuldades que caracterizam 0 ato de escrever a "historia rerum gestarum":

"(...) primeiro porque as palavras devem estar à altura dos acontecimentos; depois, porque as criticas que se vier a fazer, a maioria pensa que tudo foi dito por antipatia $e$ despeito; quando se faz mençắo da grande virtude e glória dos bons, as coisas que alguém julga capaz de fazer, ele as aceita de bom grado, as que o superam, ele as considera como fruto da fantasia e as tem como falsas. " (De C.C. 3, 2)

Essas dificuldades, longe de obscurecê-lo, ressaltam o valor da palavra escrita, tornanndo-o idêntico ao dos feitos: só através do "dicere" é que o "facere". atinge a imortalidade. Dito de outro modo, é através da palavra que conseguimos "fazer com que a nossa memória seja a mais duradoura possivel" "memoriam nostri quam maxume longam efficere") (De C.C. 1, 3), superando, assim, não só a brevidade da vida como também a própria morte. E se pensarmos, em termos do dualismo metafísico, que a morte integra a segunda coluna - a da "physis" -, nada mais lógico que coloquemos aquilo que a supera, a palavra, na primeira coluna - a do "logos".

No final do capítulo 3, reforça Salústio a oposição "passado x presente", destacando os seguintes pares antitéticos:

\begin{tabular}{|c|c|c|}
\hline Coluna 1 & $x$ & Coluna 2 \\
\hline pudor & $x$ & audacia \\
\hline abstinentia & $x$ & largitio \\
\hline uirtus & $x$ & auaritia. (De C.C. 3, 3) \\
\hline
\end{tabular}

Saliente-se que, nessa passagem, as oposições relacionam-se especificamente à atividade política, na qual, em lugar dos elementos da coluna 1 , predominam os da coluna 2.

No último capítulo do prólogo, mais um binarismo se manifesta:

$\begin{array}{ccc}\text { Coluna 1 } & \left.\times \quad \begin{array}{l}\text { Coluna } 2 \\ \text { socordia atque desidia } \\ \text { agrumcolere } \\ \text { otium litterarium }\end{array}\right] \text { seruilia officia. (De C. C. 4, 1) }\end{array}$

Nessa oposição - que, na verdade, são duas - tornam a aparecer elementos que já figuraram em oposiçōes anteriormente referidas: "desidia" (aqui acompanhada por "socordia") apareceu, em 2, 5, como pólo oposto a "labor", e os "seruilia officia" foram mencionados, sob a designação de "servitium", em 1, 2, em oposição a "imperium". É desnecessário salientar, por evidente, a supremacia do "otium" sobre os membros da segunda coluna: 0 afastamento da vida ativa para dedicar-se ao "otium" literário é essencial para que se consiga, através da palavra, reter a vida da morte. 
Os levantamentos efetuados permitem-nos, segundo cremos, avaliar convenientemente o papel do prólogo da monografia de Salústio em análise: de um lado, ele estabelece o paradigma dentro da tradição metafísica, ou seja, dentro de uma visão dualistica, antitética da realidade, a partir da qual se pretende 0 abandono do sensivel, em busca da superação da finitude, "justamente porque o finito é negativo" (Bornheim, 1977, p. 37); de outro, esse prólogo define o papel do historiador, que, no fundo, é o mesmo que detinha o autor épico - a preservação dos fatos acontecidos da morte, a fim de que sirvam de lição para as gerações futuras.

Abstract: The essay presents an analysis of the prologue of Sallust's monograph De Coniuratione Catilinae, and it emphasizes two aspects: 1. the prologue's paradigmatic function from the point of view of the identification and study of antithetical pairs that fixing a dualistic model, shape, syntagmatically, the narrative throughout; 2. the definition of the historian's function emerging in these initial chapters of the monograph in which the identity of value between "dicere" and "facere" becomes evident.

Bibliografia

BARILLI, R. Retórica. Lisboa: Presença, 1979.

BARTHES, R. A retórica antiga: In: COHEN, Jean et alii. Pesquisas de retórica. Petrópolis: Vozes, 1975, p. 147-221. . S/Z: Paris: Seuil, 1970.

BAYET, J. Littérature latine. Paris: Armand Colin, 1965.

BESSELAAR, J. V. Introdução aos estudos históricos. 2. ed., São Paulo: Herder, 1958.

BORNHEIM, G. A. Dialética: teoria, práxis. Ensaio para uma crítica da fundamentação ontológica da dialética. Porto Alegre: Globo, São. Paulo: EDUSP, 1977.

CARDOSO, Z. A. A literatura latina. Porto Alegre: Mercado Aberto, 1989.

EARL, D. C. The political thought of Sallust. Cambridge: University Press, 1961.

JAKOBSON, R. Lingülstica e comunicação. São Paulo: Cultrix, 1969.

LAUSBERG, H. Elementos de retórica literária. 2. ed. Lisboa: Fundação Calouste Gulbenkian, 1972.

- Manual de retorica literaria. Fundamentos de una ciencia de la literatura. Madrid: Gredos, 1984. 2v.

MORA, J. F. Diccionario de filosofia. 5. ed. Buenos Aires: Sudamericana, 1965. $2 v$. 
OTÁLORA, J. R. Recursos léxicos y estilísticos del vocabulario salustiano en función del pragmatismo histórico. Revista Espaniola de Lingüistica, Madrid, v. 2, p. 297-317, 1978.

PARzIALE, M. Princípios de historiografia pragmática no proêmio do "Bellum Catilinarium" de Gaio Salústio Crispo. No prelo.

QUINTILIEN. Institution oratoire. Paris: Garnier, 1954. v. 1.

RAMBAUD, $\boldsymbol{M}$. Les prologues de Salluste et la démonstration morale dans son oeuvre. Revue des Études Latines, Paris, v. 24, p. 115-30, 1947.

SALLUSTE. Catilina. Jugurtha. Fragments des Histoires. 12. ed. Paris: Les Belles Lettres, 1980.

SALÚSTIO. A conjuração de Catilina. Introdução e tradução de Antônio da Silveira Mendonça. In: SÊNECA / SALÚSTIO. Tratado sobre a clemência. Introdução, tradução e notas de Ingeborg Braren. A conjuração de Catilina. A guerra de Jugurta. Introdução e tradução de Antônio da Silveira Mendonça. Petrópolis: Vozes, 1990. 